\title{
Effect of Carbon Dissolution Reaction on Wetting Behavior between Liquid Iron and Carbonaceous Material
}

\author{
Ko-ichiro OHNO, ${ }^{1) *}$ Takahiro MIYAKE, ${ }^{2)}$ Shintaro YANO, ${ }^{3)}$ Cao Son NGUYEN, ${ }^{3)}$ Takayuki MAEDA ${ }^{1)}$ and \\ Kazuya KUNITOMO ${ }^{1)}$
}

1) Department of Materials Science and Engineering, Faculty of Engineering, Kyushu University, 744 Motooka, Nishi-ku, Fukuoka, 819-0395 Japan. $\quad$ 2) Formerly Graduated Student, Department of Materials Process Engineering, Graduate School of Engineering, Kyushu University, Now at JX Nippon Mining \& Metals, Saganoseki Smelter \& Refinery, 3-3382 Saganoseki, Oita, 879-2201 Japan. $\quad 3)$ Graduated Student, Department of Materials Process Engineering, Graduate School of Engineering, Kyushu University, 744 Motooka, Nishi-ku, Fukuoka, 819-0395 Japan.

(Received on October 2, 2014; accepted on December 11, 2014)

\begin{abstract}
A low carbon operation is an unfavorable situation for liquid permeability around cohesive zone, because liquid volume will increase against solid coke in there. In order to keep a healthy operation with this technique, information of wetting behavior between liquid iron and coke should be correctly understood. However, there is not enough information about wetting behavior between them, because of many difficulties about wettability measurement from an active reaction between iron and carbonaceous materials. In this study, a sessile drop method with molten sample injection system was applied to measurement of wetting behavior between liquid iron and carbonaceous material at $1673 \mathrm{~K}$ for excluding reaction between samples before starting measurement. Carbonaceous material's substrates were made from mixture powder of graphite and alumina by hot press at $1873 \mathrm{~K}$. From the results, following knowledge was revealed. Molten iron samples un-saturated with carbon showed bigger values of contact angles, $110^{\circ}-120^{\circ}$, at initial stage, than apparent constant values of them, $85^{\circ}-100^{\circ}$, at latter stage. It indicated a reaction between iron and carbonaceous materials had obvious effect on wetting behavior between them due to decrease an interfacial energy during the reaction. Mixed alumina powder in the substrate prevented to wetting behavior of iron sample on carbonaceous materials, and they changed their apparent constant contact angles from $115^{\circ}$ to $130^{\circ}$. The alumina powder had effects on not only wetting behavior but also reaction between iron and carbonaceous materials.
\end{abstract}

KEY WORDS: wettability; carbon dissolution; sessile drop method with molten sample injection system; simulant coke; molten iron; carbonaceous material's substrate.

\section{Introduction}

A low carbon operation due to a big demand of $\mathrm{CO}_{2}$ suppression is becoming main stream in ironmaking process. The low carbon operation in conventional ironmaking process means to decrease charging amount of coke and other carbonaceous material to blast furnace. This action will cause non-negligible changes of gas and liquid permeability due to thinning of coke layer, because liquid volume will relatively increase against coke in the layer. This is an unfavorable situation for stable operation of blast furnace. Especially, liquid permeability around a cohesive zone has a strong effect on stability of gas flow in blast furnace. Behavior of liquid phase in coke packed bed around a cohesive zone should be correctly understood. ${ }^{1)}$

There are many researches about liquid permeability around cohesive zone. ${ }^{2-10)}$ In these works, the permeability was evaluated by amount of liquid hold-up on void of coke

\footnotetext{
* Corresponding author: E-mail: ohno@zaiko.kyushu-u.ac.jp DOI: http://dx.doi.org/10.2355/isijinternational.55.1252
}

layer. Ohgusu $\mathrm{et} \mathrm{al}^{4)}$ derived an estimation formula of static hold up, $h_{s}[-]$, as follows.

$$
h_{S}=9.96\left\{\frac{\rho_{l} g D^{2}}{|\sigma \cos \theta|}\right\}^{-1.38}
$$

where $\rho_{l}$ is density of liquid $\left[\mathrm{kg} \cdot \mathrm{m}^{-3}\right], g$ is acceleration of gravity $\left[\mathrm{m} \cdot \mathrm{s}^{-2}\right], D$ is characteristic length $[\mathrm{m}], \sigma$ is surface tension of liquid $[\mathrm{N}]$, and $\theta$ is contact angle of liquid $\left[^{\circ}\right]$.

From this equation, it can be thought the static hold up is strongly depended on physical property of liquid phase. In other words, knowledge of liquidus physical property is one of the most important information to correctly understand behavior of liquid phase around cohesive zone. In Eq. (1), 3 values of liquidus physical properties are included. Although density and surface tension are simply properties of liquid phase itself, wettability means interactions between liquid phase and other phases. The interactions makes more difficult to measure the wettability than other values, and therefore there are not enough reports of values of it. One of the biggest difficulties for the measurement is an active reac- 
tion between liquid phase and carbonaceous materials. It is thought the reaction decrease an interfacial energy between the liquid phase and carbonaceous materials. ${ }^{11)}$

The wettability is evaluated using the contact angle $\theta$, which is defined by Young's equation as follows.

$$
\sigma_{g s}=\sigma_{l s}+\sigma_{g l} \cos \theta
$$

where $\sigma_{l s}, \sigma_{g l}$, and $\sigma_{g s}$ are the interfacial energies [N] between the liquid and solid, gas and liquid, and gas and solid, respectively. From Eq. (2), it can be understood a decreasing of $\sigma_{l s}$ directly effects on the contact angle, and the reaction should have an obvious influence on the contact angel measurement.

Around the cohesive zone, liquid iron and molten slag exist as liquid phases. Both liquids have a possibility to react with carbonaceous material as follows: carbon dissolution to liquid iron and smelting reduction of molten slag. An effect of the carbon dissolution reaction on the wettability between liquid iron and carbonaceous material is focused in this study, though the wettability between molten slag and carbonaceous material is important, too. Because there is fear that existing values of the iron wettability could not be precisely evaluated because of conventional wettability measurement method. One of the most popular wettability measurement methods is the sessile drop method. In this method, a liquid sample is normally made on a substrate by melting there during heating up to measurement temperature. This procedure includes big problem when a combination of liquid and substrate is reactive, because an effect at heating process before starting measurement cannot be excluded. In order to avoid this problem, a sessile drop method with molten sample injection system was applied to measurement of wetting behavior between liquid iron and carbonaceous material in this study.

In parallel, a measurement of carbon dissolution rate into liquid iron bath was conducted to understand effect of wettability at a dissolution interface on the reaction rate. It was indicated that ash of carbonaceous material has an obvious effect on carbon dissolution into iron by many reports, ${ }^{11-20)}$ including our previous works. ${ }^{19,20)}$ Knowledge of carbon dissolution behavior coexisting with ash is necessary to correctly understand wettability between molten iron and practical carbonaceous material, because the every practical carbonaceous material, coal, coke etc., basically includes not negligible amount of ash. Although there are some reports about effect of the ash on the liquid iron wettability, their results have problems from the conventional sessile method and from complexity of natural ash in the practical carbonaceous material. ${ }^{21,22)}$

In order to simplify the ash effect on the wettability, a simulant coke made from graphite and $\mathrm{Al}_{2} \mathrm{O}_{3}$ powders was applied in this study. The purposes of this study are to evaluate a usefulness of the sessile drop method with molten sample injection system and to clarify the ash effect on the iron wettability.

\section{Experiment}

In order to investigate about effect of carbon dissolution behavior at the interface on iron wetting behavior with simulant coke, 2 kinds of experiments were conducted. One is measurement of contact angel between liquid iron and the simulant coke by sessile drop method with molten sample injection system. Another is measurement of carbon dissolution rate from the simulant coke to liquid iron.

\subsection{Experimental Sample}

Effect of ash in carbonaceous materials on molten iron wetting behavior was focused in this study. Although there are many researches about ash effect on the wettability of molten iron, they studied about practical coal or coke ash. Results of them should be contained complex effects because the ash consists of many components. ${ }^{21,22)}$ And also, volatile matter, sulfur, and fixed carbon's quality could have effects on the wettability, too. In order to simplify experimental condition, simulant coke was prepared in this study. The simulant coke was made from $\mathrm{Al}_{2} \mathrm{O}_{3}$ and graphite powder. In order to avoid an effect of sulfur on surface tension of $\mathrm{Fe}-\mathrm{C}$ liquid sample, synthetic graphite was prepared as carbonaceous material. Although $\mathrm{SiO}_{2}$ is known as main component of ash in coal and coke, it has possibility to react with graphite during making simulant coke as follows.

$$
\mathrm{SiO}_{2}+3 \mathrm{C}=\mathrm{SiC}+2 \mathrm{CO}
$$

In order to avoid influence from other factors, $\mathrm{Al}_{2} \mathrm{O}_{3}$ was applied as inert material with carbon in this study. Particle sizes of $\mathrm{Al}_{2} \mathrm{O}_{3}$ and graphite were $3 \mu \mathrm{m}$ and $-45 \mu \mathrm{m}$, respectively. $\mathrm{Al}_{2} \mathrm{O}_{3}$ powder was well mixed with graphite powder at given volume ratio of $0 \mathrm{vol} \%, 10 \mathrm{vol} \%, 20 \mathrm{vol} \%$, and 30 vol\%. Mixed powders were pressed into each shape using a graphite element hot press furnace, FVPHP-R-3 of Fuji Dempa Kogyo, under Ar atmosphere at $1873 \mathrm{~K}$ with holding time of $30 \mathrm{~min}$, and a constant $3.0 \mathrm{MPa}$ applied pressure. The furnace was heated at a constant heating rate of $15 \mathrm{~K} /$ min and cooled by cutting the furnace power off.

Shape of substrate for contact angle measurement was a plate of $20 \mathrm{~mm}$ square and $5 \mathrm{~mm}$ thickness. A sample's shape for carbon dissolution experiment was a rod of $10 \mathrm{~mm}$ diameter and $25 \mathrm{~mm}$ length. The substrates were polished to uniform their surface roughness by emery paper of \#3000. Table 1 shows porosities of all of carbonaceous material samples measured by Archimedean method.

$\mathrm{Fe}-\mathrm{C}$ samples for both experiments were made from high purity electrolytic iron and graphite. These samples materials were mixed and each $1000 \mathrm{~g}$ of them were melted by induction furnace in $\mathrm{Al}_{2} \mathrm{O}_{3}$ crucible under $\mathrm{Ar}$ atmosphere. In case of contact angle measurement, carbon concentrations of $\mathrm{Fe}-\mathrm{C}$ samples were decided based on a saturated carbon concentration of iron, 4.89 mass $\%$, at the measurement temperature, 1673 K. 3 kinds of samples for this measure-

Table 1. Physical properties of carbonaceous material samples.

\begin{tabular}{llcc}
\hline & & Density $\left(\mathrm{g} / \mathrm{cm}^{3}\right)$ & Void Ratio (vol\%) \\
\hline $0 \% \mathrm{Al}_{2} \mathrm{O}_{3}$ & Substrate & 1.797 & 20.5 \\
& Rod & 1.542 & 31.8 \\
\hline \multirow{2}{*}{$10 \% \mathrm{Al}_{2} \mathrm{O}_{3}$} & Substrate & 2.036 & 16.3 \\
& Rod & 1.525 & 37.3 \\
\hline $20 \% \mathrm{Al}_{2} \mathrm{O}_{3}$ & Substrate & 2.243 & 13.8 \\
\hline $30 \% \mathrm{Al}_{2} \mathrm{O}_{3}$ & Substrate & 2.547 & 8.2 \\
\hline
\end{tabular}


ment were prepared. Their carbon content were 4.90 mass $\%$, $4.31 \mathrm{mass} \%$ and 3.56 mass $\%$. In case of carbon dissolution experiment, carbon concentrations of $\mathrm{Fe}-\mathrm{C}$ were decided to leave enough capacity for carbon dissolution at each experimental temperature as shown in Table 2.

\subsection{Experimental Procedure}

For contact angle measurement, sessile drop method with molten $\mathrm{Fe}-\mathrm{C}$ injection system was applied in this study. A schematic illustration of apparatus for this measurement was shown in Fig. 1. The apparatus consisted of combination between a graphite element furnace and a molten sample injection system. The furnace has a sapphire window to allow in situ measurements of the wetting angle. The injection system consists of an $\mathrm{Al}_{2} \mathrm{O}_{3}$ funnel part and an $\mathrm{Al}_{2} \mathrm{O}_{3}$ pushing bar as shown in Fig. 1. They were used for holding a sample and pushing the sample out from the funnel, respectively. The system was located just $10 \mathrm{~mm}$ above the substrate. Inner chamber was kept as highly purified $\mathrm{Ar}$ atmosphere $\left(99.995 \%, \mathrm{O}_{2}<3 \mathrm{ppm}\right)$ to protect $\mathrm{Fe}-\mathrm{C}$ sample and graphite heater from effect of oxygen.

The sample substrate and the injection system were heated at $15 \mathrm{~K} / \mathrm{min}$ to $1673 \mathrm{~K}$ and kept for $30 \mathrm{~min}$ to make them isothermal condition. After holding $30 \mathrm{~min}$ at $1673 \mathrm{~K}$, the molten $\mathrm{Fe}-\mathrm{C}$ sample was injected on the substrate. From this injected moment, a digital camera was used to capture images of the droplet on the substrate at $1673 \mathrm{~K}$ for $30 \mathrm{~min}$. In order to avoid effect from iron droplet vibration due to dropping from the funnel, time $0 \mathrm{~s}$ was defined as after a lapse of $10 \mathrm{~s}$ from the injected moment in this measurement. From these captured images, the contact angles between

Table 2. Carbon concentrations of iron samples for experiments.

\begin{tabular}{cccc}
\hline & $\begin{array}{c}\text { Experimental } \\
\text { Temperature (K) }\end{array}$ & $\begin{array}{c}\text { Carbon } \\
\text { concentration } \\
(\text { mass\%) }\end{array}$ & $\begin{array}{c}\text { Carbon } \\
\text { saturating } \\
\text { concentration } \\
\text { (mass\%) }\end{array}$ \\
\hline $\begin{array}{c}\text { Wettability } \\
\text { measurement }\end{array}$ & 1673 & 4.90 & 4.89 \\
\hline $\begin{array}{c}\text { Measurement } \\
\text { of carbon }\end{array}$ & 1573 & 4.31 & 4.64 \\
dissolution rate & 1623 & 3.56 & 4.77 \\
\hline
\end{tabular}

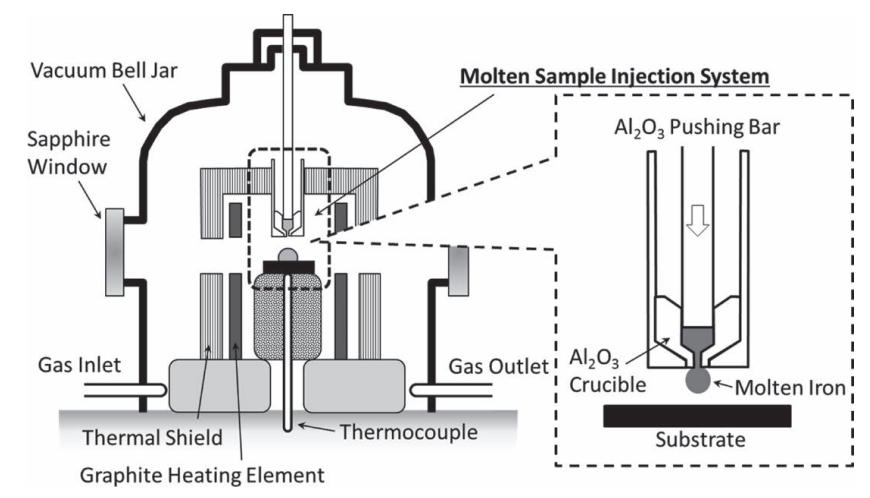

Fig. 1. A schematic illustration of sessile drop method with molten $\mathrm{Fe}-\mathrm{C}$ injection system. the substrate and the molten $\mathrm{Fe}-\mathrm{C}$ sample were measured. After the measurement, the furnace was cooled by cutting the furnace power off.

A cooled sample was embedded into resin, and polished using $1 \mu \mathrm{m}$ diamond paste for observation of interface between the substrate and the molten $\mathrm{Fe}-\mathrm{C}$ sample. A polished sample was observed by optical microscope, and analyzed $\mathrm{Al}_{2} \mathrm{O}_{3}$ distribution at the interface by Energy Dispersive X-ray spectrometry (EDS), SEM-EDX500 of Shimazu.

For carbon dissolution rate measurement, a high frequency induction heating furnace was used under Ar atmosphere as same as previous work. ${ }^{19)}$ The $\mathrm{Fe}-\mathrm{C}$ sample was put into $\mathrm{Al}_{2} \mathrm{O}_{3}$ crucible, $45 \mathrm{~mm}$ height and $38 \mathrm{~mm}$ diameter, in the $100 \mathrm{~g}$. The crucible filled with the $\mathrm{Fe}-\mathrm{C}$ sample was set into center of isothermal zone in the furnace. Surface temperature of $\mathrm{Fe}-\mathrm{C}$ liquid sample was measured by pyro scope during this measurement. It was thought the surface temperature was represent of bulk temperature of $\mathrm{Fe}-\mathrm{C}$ liquid sample because the $\mathrm{Fe}-\mathrm{C}$ sample was strongly agitated by electromagnetic force of high frequency induction furnace. The rod of carbon sample was hold just above the crucible until the $\mathrm{Fe}-\mathrm{C}$ sample was heated up to predefined temperature. In Ar atmosphere, the carbon rod was soaked for predefined time in molten $\mathrm{Fe}-\mathrm{C}$ sample $10 \mathrm{~mm}$ depth at given experiment temperature. After the soaking, $2 \mathrm{~g}$ of the $\mathrm{Fe}-\mathrm{C}$ sample was sucked up using $\mathrm{SiO}_{2}$ tube per several minutes.

The carbon concentrations of the collected $\mathrm{Fe}-\mathrm{C}$ samples were measured by infrared absorption technique in order to measure carbon dissolution rate. After a lapse of $720 \mathrm{sec}-$ onds when last sampling of $\mathrm{Fe}-\mathrm{C}$ liquid was finished, the carbon rod was pulled out from $\mathrm{Fe}-\mathrm{C}$ liquid and quenched under Ar flow. Some parts of $\mathrm{Fe}-\mathrm{C}$ sample were stayed sticking on the rod when it was pulled out. The quenched carbon rod was embedded into resin, and polished using 1 $\mu \mathrm{m}$ diamond paste for observation of interface between the rod and the molten $\mathrm{Fe}-\mathrm{C}$ sample.

\section{Experiment Results}

\subsection{Measurement Results of Contact Angle of Molten Iron on Simulant Coke}

Figures $\mathbf{2}$ and $\mathbf{3}$ show time dependency of contact angles

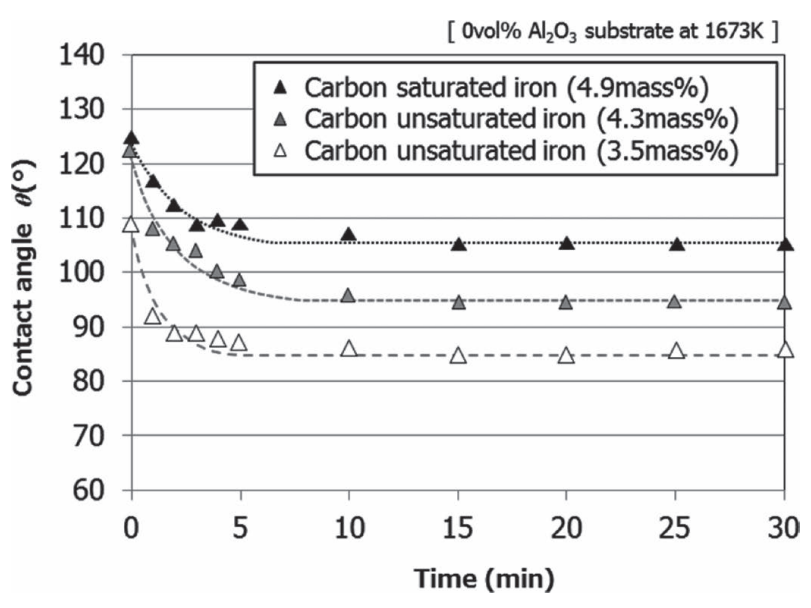

Fig. 2. Effect of carbon concentration in iron sample on wettability of $0 \mathrm{vol} \% \mathrm{Al}_{2} \mathrm{O}_{3}$ substrate at $1673 \mathrm{~K}$. 
with different carbon content $\mathrm{Fe}-\mathrm{C}$ samples using no $\mathrm{Al}_{2} \mathrm{O}_{3}$ substrate and with carbon saturated $\mathrm{Fe}-\mathrm{C}$ samples using different $\mathrm{Al}_{2} \mathrm{O}_{3}$ content substrates, respectively. These results showed same tendencies, that contact angles were gradually decreased from initial values and kept at constant values after the elapse of a certain period of time. From Fig. 2, contact angles were decreased with decreasing carbon content in $\mathrm{Fe}-\mathrm{C}$ sample. From Fig. 3, contact angles were increased with increasing $\mathrm{Al}_{2} \mathrm{O}_{3}$ content in the simulant coke substrate.

Optical micrographs of the cooled sample's interface were shown in Fig. 4. It was confirmed that intrusions of the $\mathrm{Fe}-\mathrm{C}$ sample into the substrate occurred even to carbon saturated $\mathrm{Fe}-\mathrm{C}$ samples.

\subsection{Carbon Dissolution Rate from Simulant Coke to Fe-C Liquid}

Figure 5 shows results of carbon dissolution amounts measurement from simulant coke, containing 10 volume $\%$ $\mathrm{Al}_{2} \mathrm{O}_{3}$, at 3 different temperatures. The amounts were increased with increasing of time and experimental temperatures.

In order to estimate carbon dissolution rate, following assumptions were adopted in this study as same as previous report. ${ }^{19)}$ Mass transfer in molten iron could be ignored due to enough strong agitation of molten iron by electromagnetic stirring power due to high frequency induction heating system. This means a rate determining step of carbon dissolution reaction in this study would be interfacial chemical reaction. This assumption was found reasonable from consistent agreement between experimental results and analyses, although surface flow on carbon rod could not be strictly confirmed. The soaked carbon rod kept cylindrical shape during dissolution reaction progress.

A fundamental equation for carbon mass balance between carbon rod and iron bath could be described as Eq. (4).

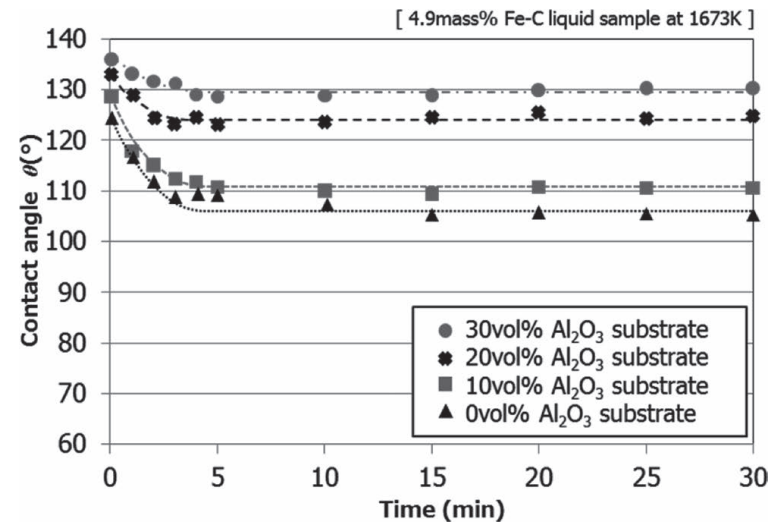

Fig. 3. Effect of $\mathrm{Al}_{2} \mathrm{O}_{3}$ content in the simulant coke substrate on wettability of 4.9 mass $\% \mathrm{Fe}-\mathrm{C}$ liquid sample at $1673 \mathrm{~K}$.

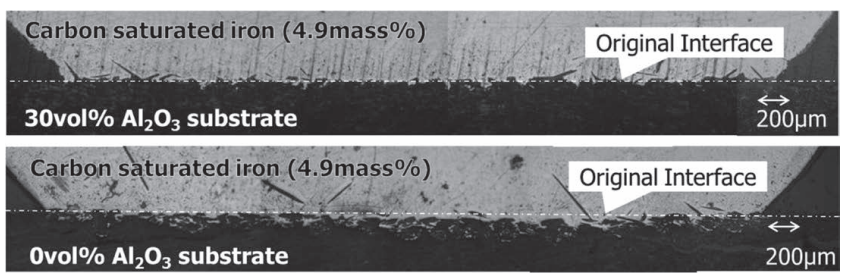

Fig. 4. Optical micrographs of the cooled sample's interfaces.

$$
-\left(\frac{d m}{d t}\right)=2 \pi r l k
$$

where, $t$ is reaction time $[\mathrm{s}], m$ is carbon content in carbon $\operatorname{rod}[\mathrm{g}], r$ is distance from center of the rod to reaction interface [cm], $l$ is depth of the rod into iron bath [cm], and $k$ is reaction rate constant $\left[\mathrm{g} / \mathrm{cm}^{2} \mathrm{~s}\right]$.

An initial condition and a boundary condition are shown as follows.

$$
\begin{gathered}
t=0 ; m=m_{0}, r=r_{0} \\
t=t ; m=m, r=r .
\end{gathered}
$$

where, $m_{0}$ is initial carbon content of the rod [g], and $r_{0}$ is initial radius of the $\operatorname{rod}[\mathrm{cm}]$.

From these equations, Eqs. (7) and (8) was obtained as known Manpel's equation. ${ }^{23)}$

$$
\begin{gathered}
1-(1-\alpha)^{\frac{1}{2}} \frac{m_{0}}{\pi r_{0} l}=k t . \\
\alpha=1-\frac{m}{m_{0}} \ldots \ldots . . .
\end{gathered}
$$

Figure 6 shows relationships between reaction time and left-hand values of Eq. (7) at $1673 \mathrm{~K}$. From gradients of these relationships, reaction rate constants $\mathrm{k}$ of each experimental condition could be calculated. From this result, carbon dissolution rate of $0 \% \mathrm{Al}_{2} \mathrm{O}_{3}$ rod was obviously higher

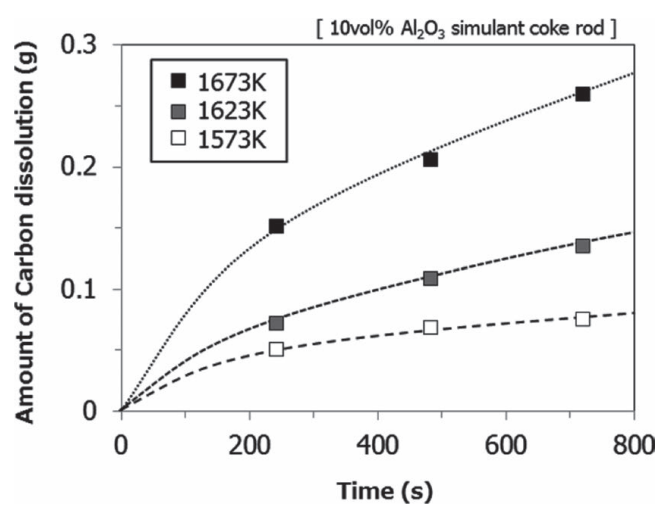

Fig. 5. Carbon dissolution behavior from 10 vol $\% \mathrm{Al}_{2} \mathrm{O}_{3}$ simulant coke rod at different temperatures.

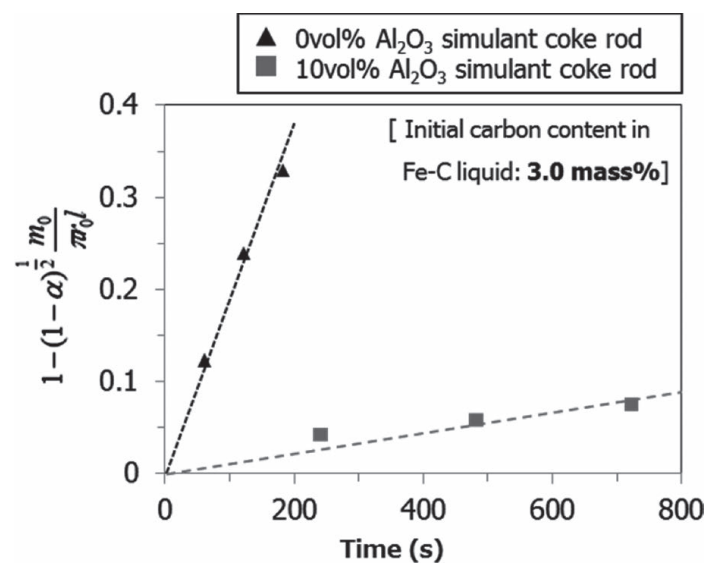

Fig. 6. Relationships between reaction time and left-hand values of Eq. (7) at $1673 \mathrm{~K}$. 
than $10 \% \mathrm{Al}_{2} \mathrm{O}_{3}$ rod as shown in Table 3 .

From temperature dependencies of reaction rate constants in Fig. 6, Arrhenius plots could be drawn in Fig. 7. From this figure, activation energies, $E_{a}[\mathrm{~J}]$, were derived and showed in Fig. 7, too. It was found that the activation energies were shown almost same values.

It could be thought an effective reaction area of this carbon dissolution reaction is graphite occupancy per unit area. The graphite occupancy was evaluated from image analysis of cross-section observation as shown in Fig. 8. In order to calculate the area ratio, 5 pictures were used for each sample. Although there was 5\% dispersion, the pictures showed almost same morphology. The graphite occupancy of $0 \% \mathrm{Al}_{2} \mathrm{O}_{3}$ rod and $10 \% \mathrm{Al}_{2} \mathrm{O}_{3}$ rod were $64 \%$ and $52 \%$, respectively, as shown in Table 4 . A difference of the graphite occupancy between them was not enough to explain about 10 times difference of carbon dissolution rates between them.

From reaction interface observation of quenched sample at $1673 \mathrm{~K}$, it was found that there was obvious different of

Table 3. Reaction rate constants of carbon dissolution from 0 vol $\% \mathrm{Al}_{2} \mathrm{O}_{3}$ simulant coke and $10 \mathrm{vol} \%$ $\mathrm{Al}_{2} \mathrm{O}_{3}$ simulant coke.

\begin{tabular}{ccc}
\hline & \multicolumn{2}{c}{$\mathrm{k}\left(\mathrm{g} \cdot \mathrm{cm}^{-2} \cdot \mathrm{s}^{-1}\right)$} \\
Temperature (k) & $0 \mathrm{vol} \% \mathrm{Al}_{2} \mathrm{O}_{3}$ & $10 \mathrm{vol} \% \mathrm{Al}_{2} \mathrm{O}_{3}$ \\
\hline 1673 & $1.90 \times 10^{-3}$ & $1.12 \times 10^{-4}$ \\
1623 & $1.07 \times 10^{-3}$ & $6.80 \times 10^{-5}$ \\
1573 & $6.15 \times 10^{-4}$ & $3.90 \times 10^{-5}$ \\
\hline
\end{tabular}

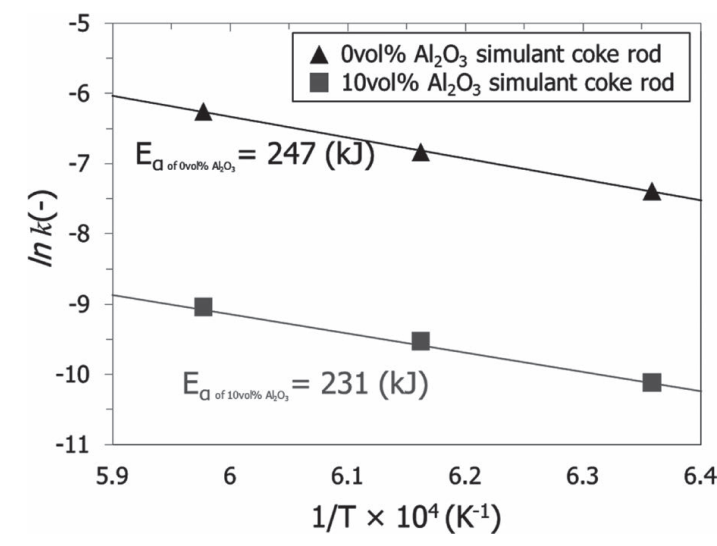

Fig. 7. Arrhenius plots of carbon dissolution reaction from simulant coke rods.
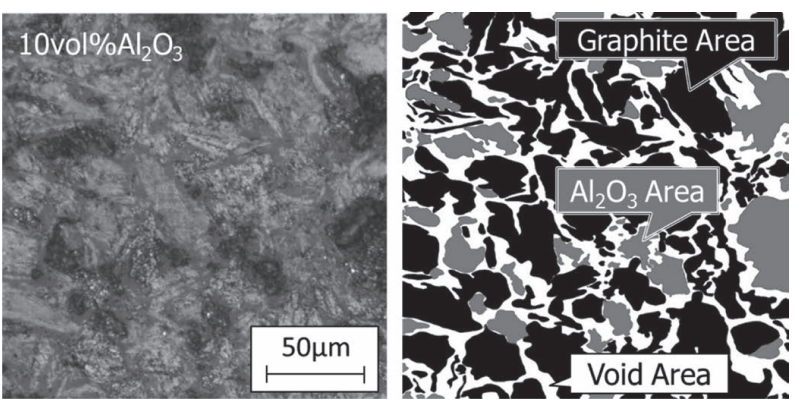

Fig. 8. Evaluation of graphite occupancy from cross-section image analysis. erosion shapes of between them, as shown in Fig. 9. In case of $0 \% \mathrm{Al}_{2} \mathrm{O}_{3}$ rod, the erosion shape was relatively complex though the shape was simple in case of $10 \% \mathrm{Al}_{2} \mathrm{O}_{3}$ rod. It was thought more complex erosion shape has larger reaction area for carbon dissolution than the simple shape. For reaction area evaluation from the erosion shape observation, erosion length per unit length was measured as follows.

A hypothetical erosion line, $L_{h}[\mu \mathrm{m}]$, was assumed as shown in line $\mathrm{H}$ of Fig. 9.

A length of $\mathrm{Fe}-\mathrm{C}$ interface, $L_{i}[\mu \mathrm{m}]$, was measured as shown in line I of Fig. 9.

A blockage length by $\mathrm{Al}_{2} \mathrm{O}_{3}$ and pore, $L_{b}[\mu \mathrm{m}]$, was measured as shown in line B of Fig. 9.

From these values, apparent effective reaction area ratio, $A_{\text {eff }}[-]$, was calculated by Eq. (9).

$$
A_{\text {eff }}=\left(\frac{L_{i}-L_{b}}{L_{h}}\right)^{2}
$$

Figure 10 shows a relationship between carbon dissolution rate and apparent effective reaction ratio. It was found that the apparent effective reaction area ratio has a bigger possibility to explain about difference of carbon dissolution reactions than the graphite occupancy per unit area in crosssection. This result indicates that the erosion shape has an obvious effect of carbon dissolution and the shape could be affected from wettability of $\mathrm{Fe}-\mathrm{C}$ liquid on the carbon rod.

\section{Discussions}

\subsection{Amount of Carbon Dissolution from Simulant Coke Substrate to Fe-C Droplet}

From Figs. 2 and 3, obvious variations between the ini-

Table 4. Area ratios of simulant coke's components evaluated from image analysis of cross-section observation.

\begin{tabular}{lccc}
\hline & Graphite (Area $\%)$ & $\mathrm{Al}_{2} \mathrm{O}_{3}($ Area $\%)$ & Pore (Area\%) \\
\hline $0 \mathrm{vol} \% \mathrm{Al}_{2} \mathrm{O}_{3}$ & 64.0 & 0 & 36.0 \\
$10 \mathrm{vol} \% \mathrm{Al}_{2} \mathrm{O}_{3}$ & 51.8 & 20.1 & 28.1 \\
\hline
\end{tabular}

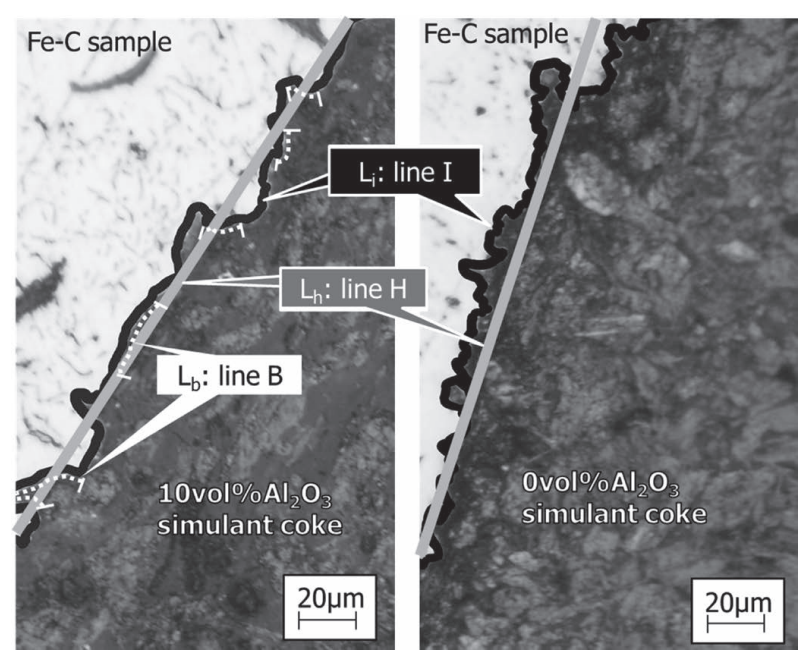

Fig. 9. Erosion shape observations for evaluation of apparent effective reaction area ratio. 


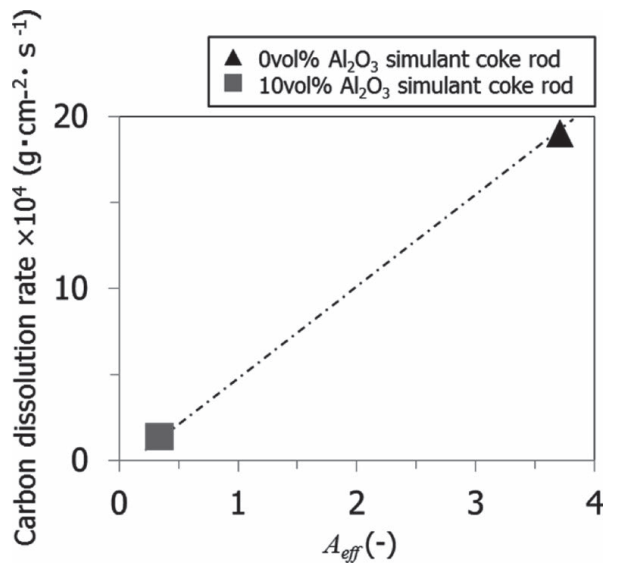

Fig. 10. Relationship between carbon dissolution rate and apparent effective reaction ratio.

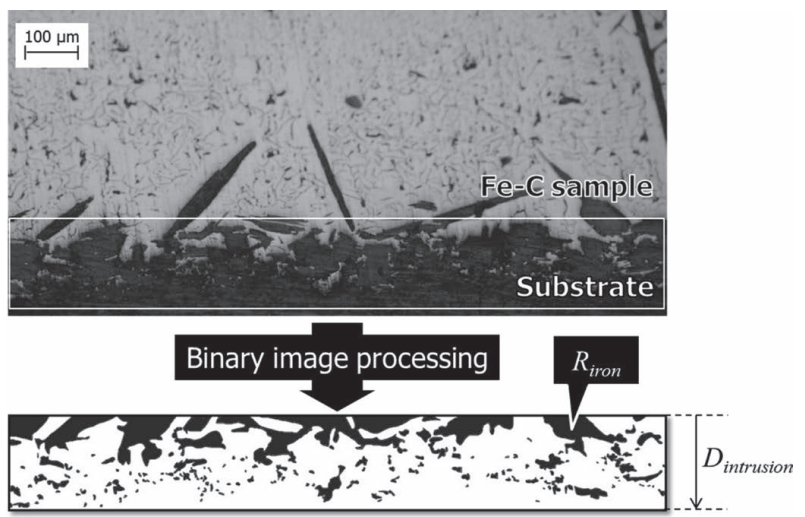

Fig. 11. Estimation of carbon dissolution amount from the optical micrograph at the interface.

tial contact angle and the constant contact angle existed. As shown in Fig. 4, it was confirmed that carbon dissolution reaction at the interface was occurred. It was thought chemical reaction at the interface would cause decreasing their interfacial tension due to decreasing of Gibbs's free energy at the interface. ${ }^{11)}$ A decrease of interfacial tension between solid and liquid causes a decrease of contact angle from Young's equation. From this reason, estimation about carbon dissolution amount into $\mathrm{Fe}-\mathrm{C}$ sample was needed for discussion about relationship between carbon dissolution reaction at the interface and variation of the contact angle in this study.

However, there was difficulty of direct measurement of carbon dissolution amount to $\mathrm{Fe}-\mathrm{C}$ sample because a complicated shape of the interface made difficult to clearly separate $\mathrm{Fe}-\mathrm{C}$ sample from the substrate. Thus, the amount of carbon dissolution was roughly estimated from image analysis as follows. From the optical micrograph at the interface, depth of iron's intrusion into the substrate, $D_{\text {intrusion }}$ $[\mathrm{cm}]$, and area ratio of iron in the substrate, $R_{\text {iron }}[-]$, were estimated as shown in Fig. 11. It was assumed that the carbon was replaced by iron due to carbon dissolution. From Eq. (10), carbon dissolution amount per unit area, $C_{\text {dissolution }}$ $\left[\mathrm{g} / \mathrm{cm}^{2}\right]$, was calculated using above mentioned values and substrate's density, $\rho_{\text {sub }}\left[\mathrm{g} / \mathrm{cm}^{3}\right]$, from Table 1 .

$$
C_{\text {dissolution }}=D_{\text {intrusion }} \times R_{\text {iron }} \times \rho_{\text {sub }}
$$

Figure 12 shows relationship between amounts of carbon

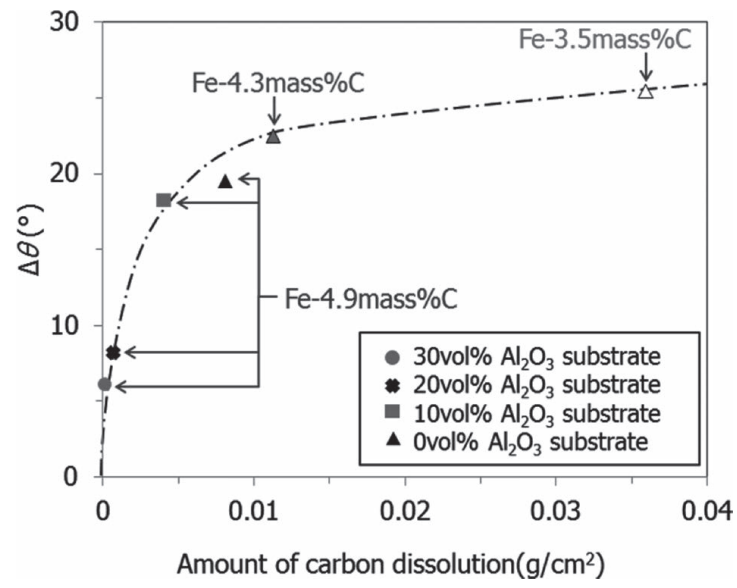

Fig. 12. Relationship between amounts of carbon dissolution and contact angle variations from the initial contact angle to the constant contact angle.

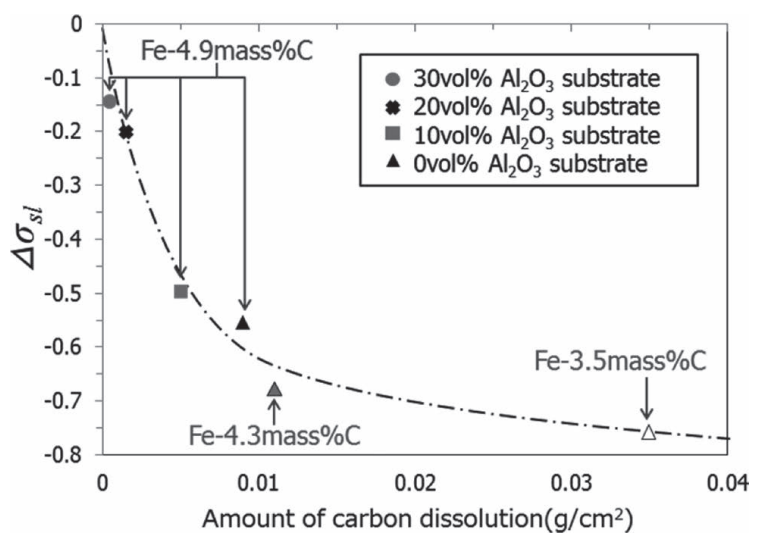

Fig. 13. Relationships between amounts of carbon dissolution and the interfacial tension variations

dissolution and contact angle variations from the initial contact angle to the constant contact angle. An obvious correlation between them was found in this figure. From the contact angle variations, variations of interfacial tension were derived by Young's equation as follows. It was assumed that surface tensions of $\mathrm{Fe}-\mathrm{C}$ liquid were not changed with variation of carbon content in $\mathrm{Fe}-\mathrm{C}$ liquid. ${ }^{24)}$ The surface tensions of liquid and solid were referred from literature values at $1673 \mathrm{~K}^{25}$ ) Initial interfacial tension and constant interfacial tension were calculated from above mentioned surface tension's values and measurement results of contact angles in this study, respectively. A subtraction from the initial interfacial tension to the constant interfacial tension was defined as the variation of interfacial tension in this study. Figure 13 shows relationships between amounts of carbon dissolution and the interfacial tension variations. From Figs. 12 and 13, it was found that a favorable condition of carbon dissolution made to decrease the contact angle due to decreasing of interfacial tensions.

These results included measurement results with carbon saturated $\mathrm{Fe}-\mathrm{C}$ sample. Carbon dissolution reaction at the interface basically could not occur in this condition. However, the evidence of the dissolution reaction was found from observation result at the interface in this study. There were possibilities of oversaturation from metastable state at the interface and/or graphite precipitation to other part 


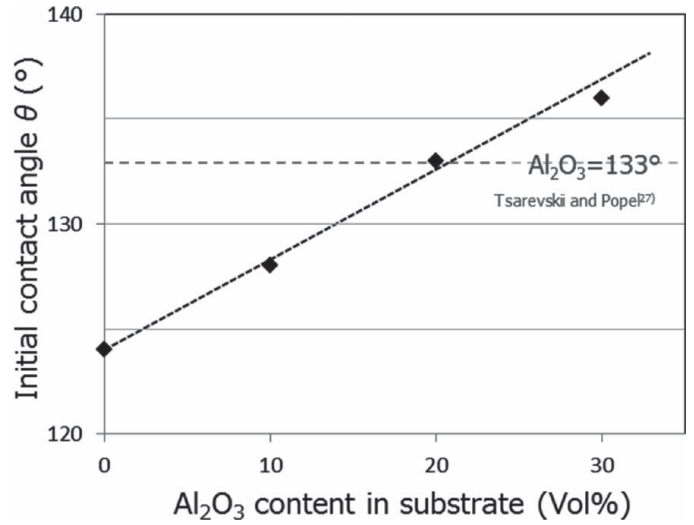

Fig. 14. Effect of $\mathrm{Al}_{2} \mathrm{O}_{3}$ content in substrate on initial contact angle.

in $\mathrm{Fe}-\mathrm{C}$ sample though it needs to discuss more in detail.

The results of carbon dissolution rate measurements were clearly indicated $\mathrm{Al}_{2} \mathrm{O}_{3}$ powder could have a negative effect of carbon dissolution reaction. It was thought the difference among carbon saturated $\mathrm{Fe}-\mathrm{C}$ sample could be caused by this effect in Fig. 13.

The result of this discussion indicated that literature values without the injection system should include a deviation from true value of the contact angle. Because ordinary sessile drop method could not avoid effect of reaction between iron sample and carbon substrate during heating up to measurement temperature. For example, M. Humenik et al. reported the contact angle of carbon saturated $\mathrm{Fe}-\mathrm{C}$ liquid on graphite substrate was $110^{\circ}$ at $1673 \mathrm{~K}^{26}$ ) This value is relatively similar as the constant value, $105^{\circ}$, but obviously different from the initial value of this study. From this comparison, it was indicated that literature value without the injection system might report smaller than true contact angle due to interfacial reaction.

\subsection{Effect of Mixed $\mathrm{Al}_{2} \mathrm{O}_{3}$ in the Substrate on Initial Contact Angle}

The initial contact angles were measured at $0 \mathrm{~s}$ as shown in Fig. 14. In other words, the effect of interfacial reaction could ideally be ignored. In that case, it was thought the contact angle could directly depend on a surface condition of the carbon substrate.

Tsarevskii and Popel $^{27)}$ reported the contact angle of carbon saturated $\mathrm{Fe}-\mathrm{C}$ liquid on $\mathrm{Al}_{2} \mathrm{O}_{3}$ substrate was $133^{\circ}$ at $1673 \mathrm{~K}$. This value is almost same as $20 \mathrm{vol} \% \mathrm{Al}_{2} \mathrm{O}_{3}$ substrate, and is smaller than 30 vol\% substrate as shown in Fig. 14. It was found that effect of $\mathrm{Al}_{2} \mathrm{O}_{3}$ addition to the substrate could not be enough reason to explain about this trend of this figure.

That means it should be necessary to consider still other effects on wetting behavior. There were several candidates of factors; effect of carbon dissolution reaction in infinitesimal time, inhomogeneous distributions of substrate's materials, etc. Their effects on the initial wetting behavior should be clarified in further next researches.

\section{Conclusions}

In order to evaluate the wettability between liquid iron and carbon substrate, the sessile drop method with molten sample injection system was applied, and the carbon dissolution rate into iron bath was measured in parallel. Following results were obtained.

Liquid iron samples un-saturated with carbon showed bigger values of contact angles at initial stage than apparent constant values of them at latter stage. It indicated that the carbon dissolution reaction could have an obvious effect on the wettability. A same trend of contact angle variation could be observed even when liquid iron sample saturated with carbon was used. It could be thought that oversaturation from metastable state at the reaction interface might occur.

Mixed alumina powder in the substrate prevented to wetting behavior of iron sample on carbonaceous materials, and they increased their apparent constant contact angles. The alumina powder had effects on not only wetting behavior but also reaction between iron and carbonaceous materials because it could change the effective contact area.

\section{Acknowledgements}

Authors express their gratitude to financial supports from ISIJ Research Promotion Grant, to scientific advices from a Research Group for Optimization of Transport Phenomena for Low Carbon Blast Furnace in ISIJ.

\section{REFERENCES}

1) M. Hayashi, S. Sukenaga, K. Ohno, S. Ueda, K. Sunahara and N. Saito: Tetsu-to-Hagané, 100 (2014), 211.

2) T. Fukutake and K. Okabe: Tetsu-to-Hagané, 66 (1980), 1947.

3) W. M.Husslage, A. G. S. Steeghs, T. Bakker, R. H. Heerema and M. A. Reuter: Proc. 60th Ironmaking Conf., ISS, Warrendale, PA, (2001), 323.

4) H. Ohgusu, Y. Sassa, Y. Tomita, K. Tanaka and M. Hasegawa: Tetsuto-Hagané, 78 (1992), 1164.

5) K. Sunahara, K. Nakano, M. Hoshi, T. Inaba, S. Komatsu and T. Yamamoto: Tetsu-to-Hagané, 92 (2006), 875.

6) T. Fukutake and V. Rajakumar: Tetsu-to-Hagané, 66 (1980), 1937.

7) H. L. Shulman, C. F. Ullrich and N. Walls: AIChE J., 1 (1955), 247.

8) H. Kawabata, Z. Liu, F. Fujita and T. Usui: Tetsu-to-Hagané, 92 (2006), 885

9) G. C. Gardner: Chem. Eng. Sci., 5 (1956), 101.

10) T. Sugiyama, T. Nakagawa, H. Sibaike and Y. Oda: Tetsu-to-Hagané, 73 (1987), 2044.

11) I. A. Aksay, C. E. Hoge and J. A. Pask: J. Phys. Chem., 78 (1974), 1178 .

12) S. Kondo and K. Ishii: Tetsu-to-Hagané, 70 (1984), A1.

13) T. Matsui, N. Ishiwata, Y. Hara and K. Takeda: ISIJ Int., 44 (2004), 2105.

14) W. Heru, K. Ohno, T. Nagasaka and M. Hino: CAMP-ISIJ, 15 (2002), 98.

15) M. W. Chapman, Brian J. Monaghan, S. A. Nightingale, J. G. Mathieson and R. J. Nightingale: ISIJ Int., 47 (2007), 973.

16) K. Ohno, T. Miki and M. Hino: ISIJ Int., 44 (2004), 2033.

17) K. Ohno, T. Miki, Y. Sasaki and M. Hino: ISIJ Int., 48 (2008), 1368.

18) K. Ohno, M. Kaimoto, T. Maeda, K. Nishioka and M. Shimizu: ISIJ Int., 51 (2011), 1279.

19) K. Ohno, A. Babich, J. Mitsue, T. Maeda, D. Senk, H. W. Gudenau and M. Shimizu: ISIJ Int., 52 (2012), 1482.

20) K. Ohno, S. Tsurumaru, A. Babich, T. Maeda, D. Senk, H. W. Gudenau and K. Kunitomo: ISIJ Int., 55 (2015), 1245.

21) C. Wu and V. Sahajwalla: Metall. Mater. Trans. B, 31B (2000), 243.

22) C. Wu, R. Wiblen and V. Sahajwalla: Metall. Mater. Trans. B, 31B (2000), 1099.

23) K. L. Manpel: Z. Phys. Chem, A187 (1940), 235.

24) K. Monma and H. Suto: J. Jpn. Inst. Met., 24 (1960), 167.

$25)$ N. Shinozaki, N, Satoh, H. Shinozaki, K. Wasai and H. Era: J. Jpn. Inst. Met., 70 (2006), 950.

26) M. Humenik, D. W. Hall and R. L. Alsten: Met. Prog., 81 (1982), 101.

27) B. V. Tsarevskii and S. I. Popel: Vuz. Chern. Metall., 8 (1960), 15. 